Article

\title{
Dynamic Changes of Flavonoids Contents in the Different Parts of Rhizome of Belamcanda chinensis During the Thermal Drying Process
}

\author{
Yan Zhu, Bing-Qing Pu, Guo-Yong Xie, Mei Tian, Fang-Yun Xu and Min-Jian Qin * \\ Department of Resources Science of Traditional Chinese Medicines, State Key Laboratory of Natural \\ Medicines, China Pharmaceutical University, Nanjing 210009, China; E-Mails: cpuzy@ 126.com (Y.Z.); \\ kypbq@163.com (B.-Q.P.); guoyongxie321@163.com (G.-Y.X.); ivytian11@ hotmail.com (M.T.); \\ xufangyun2010@163.com (F.-Y.X.)
}

* Author to whom correspondence should be addressed; E-Mail: minjianqin@ 163.com; Tel.: +86-025-86-185130; Fax: +86-025-85-301528.

Received: 16 April 2014; in revised form: 24 June 2014 / Accepted: 10 July 2014 /

Published: 17 July 2014

\begin{abstract}
The dried rhizome of Belamcanda. chinensis (L.) DC. is an important traditional Chinese medicine. Previous chemical and pharmacological investigations indicated that flavonoids may be responsible for the bioactivity of the herb. In this paper, the effects on the contents of twelve flavonoids in the three subunit parts of the rhizome of B. chinensis during the thermal drying process under treatment temperatures ranging from $40{ }^{\circ} \mathrm{C}$ to $120{ }^{\circ} \mathrm{C}$ at $10{ }^{\circ} \mathrm{C}$ intervals were investigated. The results showed that the content of most of the individual flavonoids except that of tectorigenin in the fresh eldest parts of the rhizome that originate directly from the seedling was higher than those of the other junior parts. The change trends of flavonoids contents were similar for three subunit parts of the rhizome during the drying process under the same treatment temperature. Most of the individual flavonoid contents in the rhizome increased in the early stages of the drying processes and decreased as the process was prolonged. The durations required to reaching the points of the maximal amounts of flavonoids revealed a significant negative correlation with the temperature. The variation of the content of mangiferin, iristectorigenin A, irigenin, irilone and dichotomitin was positively correlated with irisflorentin that is the chemical marker used for the quality control of this herb. Taking into account of the production effectiveness and flavonoid yields, the appropriate drying temperature for this herb was suggested to be $100{ }^{\circ} \mathrm{C}$.
\end{abstract}


Keywords: Belamcanda chinensis; thermal drying process; flavonoids; quantitation

\section{Introduction}

Belamcanda chinensis (L.) DC. (Iridaceae) is a perennial herbaceous plant mainly distributed in China, Japan, Korea, India and eastern Russia. The dried rhizome of B. chinensis (Belamcandae Rhizoma, "Shegan" in Chinese) has been used as an important traditional Chinese herb medicine for thousands of years to cure pulmonary diseases, acute and chronic pharyngitis and asthma [1]. Previous chemical and pharmacological investigations indicated that flavonoids may be responsible for the bioactivity of Belamcandae Rhizoma [2-7]. Among them, tectoridin, tectorigenin, iridin, irigenin and irisflorentin were the most abundant bioactive constituents [8].

At present, in the traditional medicinal raw materials markets in China, the major commodities of Belamcandae Rhizoma are the biennial rhizomes harvested from plantations. B. chinensis is a modular organism and its rhizome is composed of three levels of repeated, subunit parts (modules G1, G2 and G3 in Figure 1A) which are formed at different development stages of the plants. According to our previous biological research on B. chinensis [9], at the end of the first year of sowing, the young seedling of B. chinensis forms a main rhizome (the primary rhizome, grade I rhizome, G1), and 3 5 rhizomatous branches (the secondary rhizome, grade II rhizome, G2) on which 2 3 dormant buds initiate. In the second year, two or three of $\mathbf{G} 2$ rhizomatous branches possessing a growth advantage produce three or four new rhizomatous branches (the third grade rhizome, grade III rhizome, G3). Up to now, comparisons of bioactive constituents among different subunit parts of the rhizome of B. chinensis have not been reported.

Quality control of the main bioactive components is important for the safety, efficacy and consistency for herbal medicines [10]. Generally, the components of herbal medicines may be influenced by the plant breed, organ specificity, stages of growth, cultivation parameters, harvesting times, processing, and storage conditions and so on [11-17]. To produce effective and constant herbal products, attention must be paid to these influencing factors.

Drying is a crucial and fundamental procedure in the post-harvest process which may affect the quality attributes (e.g., chemical compositions or content of the active principles and bioactivities) of medicinal herbs [18-22]. Conventionally, the rhizome of B. chinensis is processed through a natural sun drying process, however, takes a long time, more than one or two months, to reach the standard level of moisture $(\leq 10.0 \%)$ documented in the Chinese Pharmacopoeia [1]. In the natural drying process of herbs, as the drying conditions are uncontrollable, this leads to the inability to guarantee the safety and consistency of active principle contents. Thermal drying is the most commonly employed commercial technique for drying herbs on an industrial scale [20]. However, so far, the influences of the thermal drying regime on the flavonoids contents of the rhizomes of B. chinensis remains to be clarified.

To provide basic information for the quality control and further optimization of the thermal drying process of $B$. chinensis, this paper reports in detail the effects of different treatment temperatures on the flavonoid contents of the herb during the thermal drying process. The comparisons of 
flavonoid contents among different growth and development level parts of the fresh rhizome were studied concurrently.

Figure 1. (A) The modules of the rhizome of B. chinensis. (G1-G3 are the primary, second and third grade, respectively) (B) The comparison of components in three parts of fresh rhizome of B. chinensis. (C) Chromatograms of authentic standards and the extracts of different grades of Blamcandae Rhizoma Peaks: 1, neomangiferin; 2, mangiferin; 3, tectoridin; 4, iristectorin $\mathrm{B} ; \mathbf{5}$, iristectorin $\mathrm{A} ; \mathbf{6}$, iridin; 7, tectorigenin; 8 , iristectorigenin A; 9, irigenin; 10, irisflorentin; 11, irilone; 12, dichotomitin.
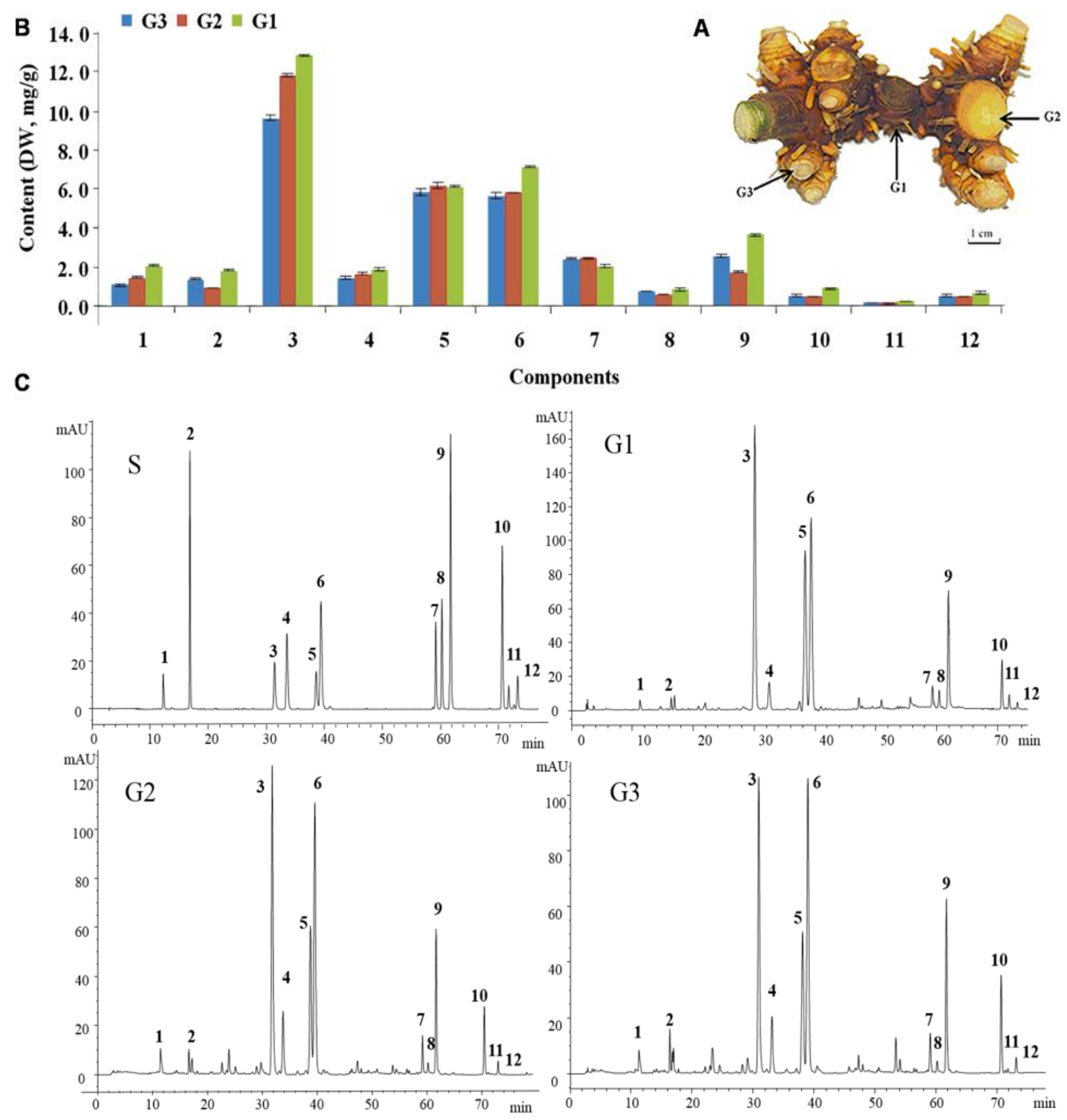


\section{Results and Discussion}

\subsection{Dehydration Curves}

Dehydration curves that indicated the changes of the moisture of the materials during the thermal drying process of the three grades of fresh rhizomes of $B$. chinensis at different temperatures are illustrated in Figure 2. The initial moisture contents of the three grades of rhizome of B. chinensis were $63.2 \% \pm 0.2 \%, 64.0 \% \pm 0.2 \%$ and $61.6 \% \pm 0.6 \%$ (wet basis), respectively. As the temperature increased, the durations required reaching the desired standard moisture $(\leq 10.0 \%)$ according to the Chinese Pharmacopoeia [1] from their initial values $(\sim 63 \%)$ of fresh materials were shortened significantly (Table 1) The drying duration reaching the desired moisture at $120{ }^{\circ} \mathrm{C}$ was only $20 \mathrm{~min}$, while $10 \mathrm{~h}$ needed when dried at $40{ }^{\circ} \mathrm{C}$. The results revealed a significant positive correlation between drying rate and treatment temperatures $(p<0.01)$.

Figure 2. Dehydration curves of samples at different drying temperatures during the thermal drying process of the three grades parts of rhizomes of B. chinensis. G1, G2 and G3 are the primary, second and third grade parts of the rhizome, respectively.
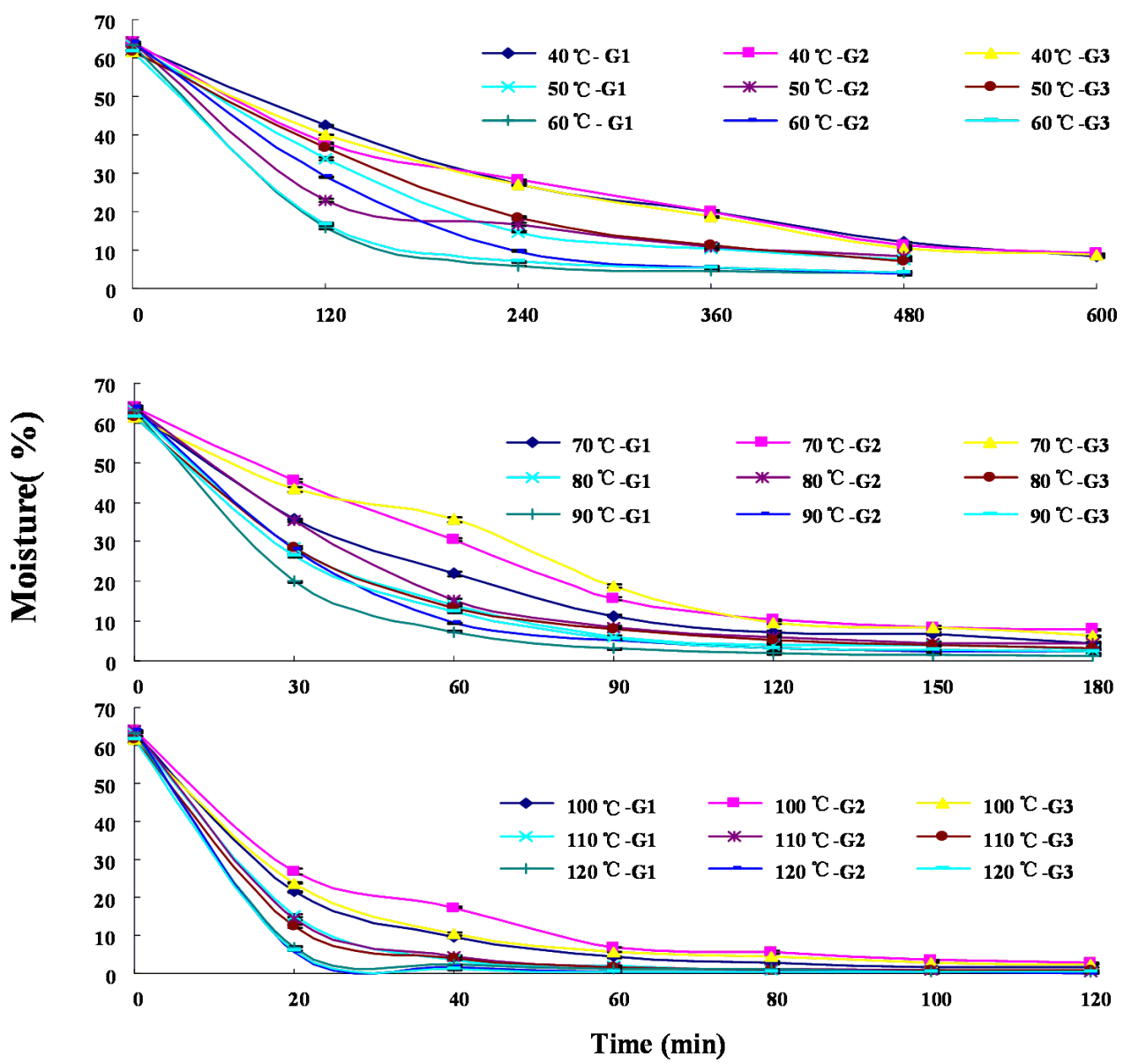
Table 1. Efficiencies and levels of twelve analytes in dried samples with standard moisture. ${ }^{\text {a }}$

\begin{tabular}{|c|c|c|c|c|c|c|c|c|c|c|c|c|c|c|c|}
\hline \multirow{2}{*}{ G. ${ }^{\mathbf{b}}$} & \multirow{2}{*}{$\mathbf{T}^{\mathrm{c}}\left({ }^{\circ} \mathbf{C}\right)$} & \multirow{2}{*}{$\begin{array}{l}\text { Time } \\
(\min )\end{array}$} & \multirow{2}{*}{ Moist. $^{d}$} & \multicolumn{12}{|c|}{ Contents of Analytes (mg/g, DW) } \\
\hline & & & & 1 & 2 & 3 & 4 & 5 & 6 & 7 & 8 & 9 & 10 & 11 & 12 \\
\hline \multirow{9}{*}{ G1 } & 40 & 600 & $8.13 \pm 0.06$ & $1.17 \pm 0.10$ & $1.23 \pm 0.06$ & $14.17 \pm 0.04$ & $1.83 \pm 0.02$ & $7.74 \pm 0.15$ & $7.21 \pm 0.04$ & $1.30 \pm 0.09$ & $0.60 \pm 0.01$ & $2.39 \pm 0.03$ & $0.49 \pm 0.01$ & $0.14 \pm 0.02$ & $1.05 \pm 0.02$ \\
\hline & 50 & 420 & $8.41 \pm 0.33$ & $2.45 \pm 0.05$ & $1.65 \pm 0.01$ & $13.32 \pm 0.01$ & $1.89 \pm 0.00$ & $6.18 \pm 0.19$ & $7.19 \pm 0.02$ & $1.32 \pm 0.00$ & $0.76 \pm 0.01$ & $3.13 \pm 0.00$ & $0.90 \pm 0.00$ & $0.21 \pm 0.01$ & $0.92 \pm 0.01$ \\
\hline & 60 & 180 & $8.53 \pm 0.32$ & $2.10 \pm 0.06$ & $1.92 \pm 0.08$ & $13.72 \pm 0.08$ & $2.01 \pm 0.05$ & $6.91 \pm 0.07$ & $8.35 \pm 0.14$ & $1.36 \pm 0.09$ & $0.86 \pm 0.05$ & $3.71 \pm 0.23$ & $1.10 \pm 0.08$ & $0.27 \pm 0.01$ & $1.00 \pm 0.00$ \\
\hline & 70 & 120 & $7.35 \pm 0.40$ & $2.10 \pm 0.23$ & $1.65 \pm 0.07$ & $11.79 \pm 0.13$ & $1.73 \pm 0.02$ & $5.83 \pm 0.03$ & $7.04 \pm 0.00$ & $1.19 \pm 0.09$ & $0.70 \pm 0.00$ & $3.13 \pm 0.08$ & $0.93 \pm 0.00$ & $0.19 \pm 0.02$ & $0.81 \pm 0.01$ \\
\hline & 80 & 90 & $6.06 \pm 0.31$ & $1.79 \pm 0.03$ & $2.09 \pm 0.14$ & $13.47 \pm 0.03$ & $2.06 \pm 0.08$ & $6.36 \pm 0.04$ & $7.72 \pm 0.10$ & $1.23 \pm 0.05$ & $0.87 \pm 0.05$ & $3.73 \pm 0.22$ & $1.28 \pm 0.10$ & $0.30 \pm 0.00$ & $1.16 \pm 0.06$ \\
\hline & 90 & 60 & $7.33 \pm 0.19$ & $1.73 \pm 0.12$ & $1.59 \pm 0.08$ & $13.69 \pm 0.26$ & $2.01 \pm 0.07$ & $6.12 \pm 0.07$ & $7.48 \pm 0.09$ & $1.04 \pm 0.03$ & $0.79 \pm 0.04$ & $3.36 \pm 0.06$ & $1.06 \pm 0.05$ & $0.26 \pm 0.00$ & $0.91 \pm 0.03$ \\
\hline & 100 & 40 & $9.69 \pm 0.35$ & $1.69 \pm 0.03$ & $1.74 \pm 0.00$ & $13.25 \pm 0.03$ & $2.07 \pm 0.17$ & $7.13 \pm 0.13$ & $8.30 \pm 0.01$ & $1.40 \pm 0.06$ & $0.97 \pm 0.00$ & $4.17 \pm 0.01$ & $1.38 \pm 0.01$ & $0.33 \pm 0.01$ & $1.25 \pm 0.02$ \\
\hline & 110 & 40 & $3.57 \pm 0.16$ & $1.83 \pm 0.01$ & $1.64 \pm 0.01$ & $12.34 \pm 0.00$ & $1.90 \pm 0.01$ & $6.05 \pm 0.04$ & $7.94 \pm 0.01$ & $1.03 \pm 0.04$ & $0.79 \pm 0.02$ & $3.39 \pm 0.06$ & $1.00 \pm 0.02$ & $0.24 \pm 0.00$ & $0.91 \pm 0.00$ \\
\hline & 120 & 20 & $7.00 \pm 0.35$ & $1.61 \pm 0.07$ & $1.85 \pm 0.03$ & $12.20 \pm 0.04$ & $1.90 \pm 0.09$ & $6.09 \pm 0.03$ & $7.04 \pm 0.05$ & $1.03 \pm 0.03$ & $0.87 \pm 0.07$ & $3.42 \pm 0.05$ & $0.91 \pm 0.17$ & $0.25 \pm 0.04$ & $0.71 \pm 0.04$ \\
\hline \multirow{9}{*}{ G2 } & 40 & 600 & $9.03 \pm 0.12$ & $0.99 \pm 0.00$ & $1.11 \pm 0.07$ & $15.66 \pm 0.27$ & $1.81 \pm 0.01$ & $6.59 \pm 0.11$ & $5.97 \pm 0.01$ & $1.03 \pm 0.02$ & $0.61 \pm 0.03$ & $1.86 \pm 0.00$ & $0.40 \pm 0.01$ & $0.13 \pm 0.01$ & $0.67 \pm 0.00$ \\
\hline & 50 & 420 & $8.40 \pm 0.15$ & $0.98 \pm 0.01$ & $1.46 \pm 0.01$ & $12.11 \pm 0.18$ & $1.66 \pm 0.03$ & $6.20 \pm 0.06$ & $6.65 \pm 0.03$ & $0.88 \pm 0.03$ & $0.63 \pm 0.01$ & $2.34 \pm 0.06$ & $0.67 \pm 0.02$ & $0.18 \pm 0.01$ & $0.55 \pm 0.02$ \\
\hline & 60 & 240 & $9.62 \pm 0.17$ & $1.12 \pm 0.00$ & $1.25 \pm 0.05$ & $14.59 \pm 0.29$ & $1.84 \pm 0.01$ & $6.99 \pm 0.12$ & $7.32 \pm 0.14$ & $1.15 \pm 0.01$ & $0.70 \pm 0.02$ & $2.47 \pm 0.06$ & $0.64 \pm 0.01$ & $0.16 \pm 0.01$ & $0.73 \pm 0.01$ \\
\hline & 70 & 150 & $8.39 \pm 0.23$ & $1.01 \pm 0.01$ & $1.28 \pm 0.01$ & $11.86 \pm 0.27$ & $1.59 \pm 0.01$ & $6.40 \pm 0.13$ & $6.69 \pm 0.10$ & $1.04 \pm 0.02$ & $0.73 \pm 0.02$ & $2.61 \pm 0.06$ & $0.64 \pm 0.01$ & $0.16 \pm 0.00$ & $0.62 \pm 0.01$ \\
\hline & 80 & 90 & $8.51 \pm 0.31$ & $1.13 \pm 0.04$ & $1.62 \pm 0.03$ & $11.48 \pm 0.32$ & $1.73 \pm 0.05$ & $6.28 \pm 0.17$ & $7.07 \pm 0.14$ & $1.15 \pm 0.02$ & $0.83 \pm 0.03$ & $3.18 \pm 0.02$ & $0.88 \pm 0.01$ & $0.20 \pm 0.01$ & $0.96 \pm 0.04$ \\
\hline & 90 & 60 & $9.53 \pm 0.23$ & $1.10 \pm 0.05$ & $1.22 \pm 0.03$ & $11.56 \pm 0.12$ & $1.62 \pm 0.01$ & $5.66 \pm 0.03$ & $6.25 \pm 0.00$ & $1.22 \pm 0.01$ & $0.83 \pm 0.02$ & $2.78 \pm 0.04$ & $0.73 \pm 0.02$ & $0.18 \pm 0.01$ & $0.73 \pm 0.01$ \\
\hline & 100 & 60 & $6.78 \pm 0.11$ & $1.02 \pm 0.02$ & $1.56 \pm 0.04$ & $11.55 \pm 0.14$ & $1.48 \pm 0.03$ & $6.14 \pm 0.16$ & $6.44 \pm 0.11$ & $0.98 \pm 0.01$ & $0.85 \pm 0.03$ & $3.40 \pm 0.06$ & $1.02 \pm 0.04$ & $0.25 \pm 0.01$ & $0.80 \pm 0.01$ \\
\hline & 110 & 40 & $4.41 \pm 0.38$ & $1.23 \pm 0.01$ & $1.54 \pm 0.02$ & $11.71 \pm 0.34$ & $1.62 \pm 0.03$ & $5.86 \pm 0.10$ & $6.17 \pm 0.16$ & $0.92 \pm 0.01$ & $0.68 \pm 0.02$ & $2.73 \pm 0.02$ & $0.76 \pm 0.02$ & $0.20 \pm 0.01$ & $0.74 \pm 0.03$ \\
\hline & 120 & 20 & $5.53 \pm 0.31$ & $1.18 \pm 0.03$ & $1.03 \pm 0.07$ & $11.34 \pm 0.29$ & $1.55 \pm 0.04$ & $5.52 \pm 0.13$ & $6.89 \pm 0.11$ & $1.06 \pm 0.03$ & $0.78 \pm 0.02$ & $1.86 \pm 0.04$ & $0.77 \pm 0.03$ & $0.19 \pm 0.01$ & $0.56 \pm 0.02$ \\
\hline \multirow{9}{*}{ G3 } & 40 & 600 & $8.57 \pm 0.13$ & $1.08 \pm 0.01$ & $1.53 \pm 0.00$ & $13.64 \pm 0.01$ & $1.75 \pm 0.00$ & $6.28 \pm 0.03$ & $5.81 \pm 0.02$ & $1.38 \pm 0.11$ & $0.69 \pm 0.00$ & $2.85 \pm 0.07$ & $0.50 \pm 0.02$ & $0.14 \pm 0.00$ & $0.49 \pm 0.04$ \\
\hline & 50 & 420 & $7.57 \pm 0.09$ & $1.1 \pm 0.05$ & $1.9 \pm 0.00$ & $11.5 \pm 0.00$ & $1.7 \pm 0.00$ & $6.4 \pm 0.00$ & $6.4 \pm 0.00$ & $1.2 \pm 0.00$ & $0.8 \pm 0.00$ & $3.2 \pm 0.01$ & $0.6 \pm 0.01$ & $0.2 \pm 0.00$ & $0.6 \pm 0.00$ \\
\hline & 60 & 240 & $7.01 \pm 0.16$ & $1.06 \pm 0.00$ & $1.96 \pm 0.00$ & $11.20 \pm 0.00$ & $1.70 \pm 0.00$ & $6.08 \pm 0.00$ & $6.04 \pm 0.00$ & $1.43 \pm 0.00$ & $0.83 \pm 0.00$ & $3.73 \pm 0.00$ & $0.71 \pm 0.00$ & $0.18 \pm 0.00$ & $0.74 \pm 0.00$ \\
\hline & 70 & 120 & $9.51 \pm 0.43$ & $1.38 \pm 0.01$ & $1.68 \pm 0.18$ & $10.85 \pm 0.10$ & $1.44 \pm 0.14$ & $6.25 \pm 0.06$ & $5.58 \pm 0.05$ & $1.55 \pm 0.19$ & $0.88 \pm 0.09$ & $3.86 \pm 0.05$ & $0.59 \pm 0.05$ & $0.20 \pm 0.00$ & $0.71 \pm 0.00$ \\
\hline & 80 & 90 & $8.16 \pm 0.31$ & $1.00 \pm 0.05$ & $1.61 \pm 0.06$ & $11.41 \pm 0.50$ & $1.58 \pm 0.04$ & $6.02 \pm 0.23$ & $5.65 \pm 0.05$ & $1.14 \pm 0.06$ & $0.78 \pm 0.03$ & $3.26 \pm 0.01$ & $0.55 \pm 0.01$ & $0.17 \pm 0.00$ & $0.62 \pm 0.00$ \\
\hline & 90 & 90 & $5.44 \pm 0.30$ & $1.05 \pm 0.01$ & $1.82 \pm 0.11$ & $11.24 \pm 0.03$ & $1.79 \pm 0.06$ & $7.18 \pm 0.02$ & $6.86 \pm 0.14$ & $1.07 \pm 0.08$ & $0.81 \pm 0.03$ & $3.63 \pm 0.29$ & $0.69 \pm 0.08$ & $0.20 \pm 0.03$ & $0.59 \pm 0.04$ \\
\hline & 100 & 60 & $5.62 \pm 0.15$ & $0.98 \pm 0.03$ & $1.56 \pm 0.12$ & $10.64 \pm 0.08$ & $1.57 \pm 0.05$ & $6.50 \pm 0.04$ & $5.96 \pm 0.14$ & $1.32 \pm 0.03$ & $0.90 \pm 0.05$ & $3.94 \pm 0.25$ & $0.72 \pm 0.02$ & $0.21 \pm 0.00$ & $0.87 \pm 0.00$ \\
\hline & 110 & 40 & $4.00 \pm 0.25$ & $0.96 \pm 0.03$ & $1.82 \pm 0.08$ & $10.52 \pm 0.19$ & $1.59 \pm 0.04$ & $6.80 \pm 0.15$ & $6.89 \pm 0.23$ & $1.11 \pm 0.07$ & $0.87 \pm 0.08$ & $3.71 \pm 0.03$ & $0.79 \pm 0.10$ & $0.21 \pm 0.01$ & $0.93 \pm 0.01$ \\
\hline & 120 & 20 & $5.99 \pm 0.19$ & $0.99 \pm 0.04$ & $1.49 \pm 0.00$ & $10.30 \pm 0.44$ & $1.52 \pm 0.09$ & $6.38 \pm 0.19$ & $6.15 \pm 0.20$ & $0.89 \pm 0.06$ & $0.71 \pm 0.03$ & $3.31 \pm 0.11$ & $0.67 \pm 0.04$ & $0.20 \pm 0.00$ & $0.68 \pm 0.01$ \\
\hline
\end{tabular}

${ }^{a}$ Results are mean values of triplicate assays; Content is the value of dry weight; ${ }^{b}$ Grade; ${ }^{c}$ Temperature; ${ }^{d}$ Moisture (\%). Numbering of the compounds is,

1, neomangiferin; 2, mangiferin; 3, tectoridin; 4, iristectorin B; 5, iristectorin A; 6, iridin; 7, tectorigenin; 8, iristectorigenin A; 9, irigenin; 10, irisflorentin; 11, irilone;

12, dichotomitin. 


\subsection{Determination of Analytes}

In this research, our previous established HPLC-UV method for the simultaneous determination of the twelve analytes in Belamcandae Rhizoma was used [9], by which all twelve analytes (1 12) were well resolved with good peak symmetry (Figure 1C). This quantitative method was fully validated. The calibration curve, detection limit and quantification limit, and linear range for each analyte were provided in Supplementary Table S1. The recoveries of the twelve investigated components ranged from $97.97 \%$ to $104.08 \%$. The intra- and inter-day precisions (RSD) were in the range of $0.92 \% \sim 2.15 \%$ and $1.94 \% \sim 3.54 \%$, respectively. All the results revealed a high sensitivity and good linearity of the method. The results of determination of twelve flavonoids contents in three grades of rhizome of B. chinensis from different sampling points during drying process at different temperature were provided in Supplementary Tables S2-S4.

\subsection{Differences of the Flavonoids Contents in Three Subunit Parts of Belamcandae Rhizoma}

The main bioactivities of Belamcandae Rhizoma are ascribed to its abundant flavonoids, including isoflavonoid- $O$-glucosides, isoflavonoid aglycones and xanthones which contribute to estrogenic, antioxidative and anti-cancer effects [4,23-25]. The predominant isoflavonoid- $O$-glucosides in the Belamcandae Rhizoma include tectoridin (3), iristectorin A (4), iristectorin B (5) and iridin (6). The major flavonoid aglycones are tectorigenin (7), iristectorigenin A (8), irigenin (9), irisflorentin (10), irilone (11) and dichotomitin (12). The major xanthones in the rhizome are neomangiferin (1) and mangiferin (2), which are also flavonoid-glucosides. The results revealed that the contents of most of the ingredients except tectorigenin (7) in the fresh G1 were significantly higher than those of the fresh G2 and G3 (Figure 1B). The content of tectoridin (3), the main ingredient in the fresh G1 was $12.85 \pm 0.06 \mathrm{mg} / \mathrm{g} \mathrm{DW}$, while the contents of those in the fresh $\mathbf{G 2}$ and $\mathbf{G 3}$ were $11.87 \pm 0.07 \mathrm{mg} / \mathrm{g}$ DW and $9.65 \pm 0.03 \mathrm{mg} / \mathrm{g}$ DW, respectively. The differences of the flavonoids contents between fresh G2 and G3 were also significant, except iridin (6), tectorigenin (7), irisflorentin (10) and dichotomitin (12). The contents of neomangiferin (1), tectoridin (3), iristectorin B (4), iristectorin A (5) in the fresh G2 were slightly higher than those of fresh G3, while contents of mangiferin (2), iristectorigenin A (8), irigenin (9) and irilone (11) in the fresh G2 were slightly lower than those in fresh G3 (Figure 1B). The results indicated that the elder parts of the rhizome accumulated more amounts of flavonoid than the junior ones. It might be due to the characteristic chemical ingredients distribution in the different tissues of the rhizome. According to our preliminary study on histochemical analysis of the rhizome of $B$. chinensis, xanthones and isoflavonoid aglycones distribute mainly in the external cork cell layer of the rhizomes, while isoflavonoid- $O$-glucosides mainly locate in the internal parenchyma cells and vascular bundle tissue cells (unpublished data). When the rhizomes were separated into three subunit parts, the $\mathbf{G 2}$ possessed the least proportion of external cork cells layer to internal tissues, which might explain that the contents of most isoflavonoid aglycones in the fresh G2 were slightly lower than those in fresh G3. The similar phenomenon was also observed in the root of Salvia miltiorrhiza and the report indicated that the lipophilic diterpenoid quinonoes mainly distributed in the bark and increased with the cultivated years [26]. 


\subsection{Dynamic Changes of Flavonoids in Thermal Drying Process}

During the thermal drying processes, the contents of most individual flavonoids and the total sum content of twelve flavonoids (TFs) in the rhizome of B. chinensis increased in the early stages of the thermal drying processes and decreased as the processes prolonged (Figure 3). The duration reaching the points of maximum flavonoids contents showed a negative correlation with treatment temperatures. The change trends of flavonoids contents in the three grades parts of the rhizome were similar during thermal drying process at the same treatment temperatures, whereas the durations when the flavonoids contents reached maximum values (apical values, $A$-values) and the rates of change at the same temperature for the three grades samples of the rhizome varied. The flavonoids contents of sufficiently dried samples ( $S$-values) of each ingredient were lower than their $A$-values due to a longer drying process the materials underwent.

Figure 3. The contents of FGs (A), FAs (B) and TFs (C) during the drying process at different temperatures. G1, grade I rhizome; G2, grade II rhizome; G3, grade III rhizome.

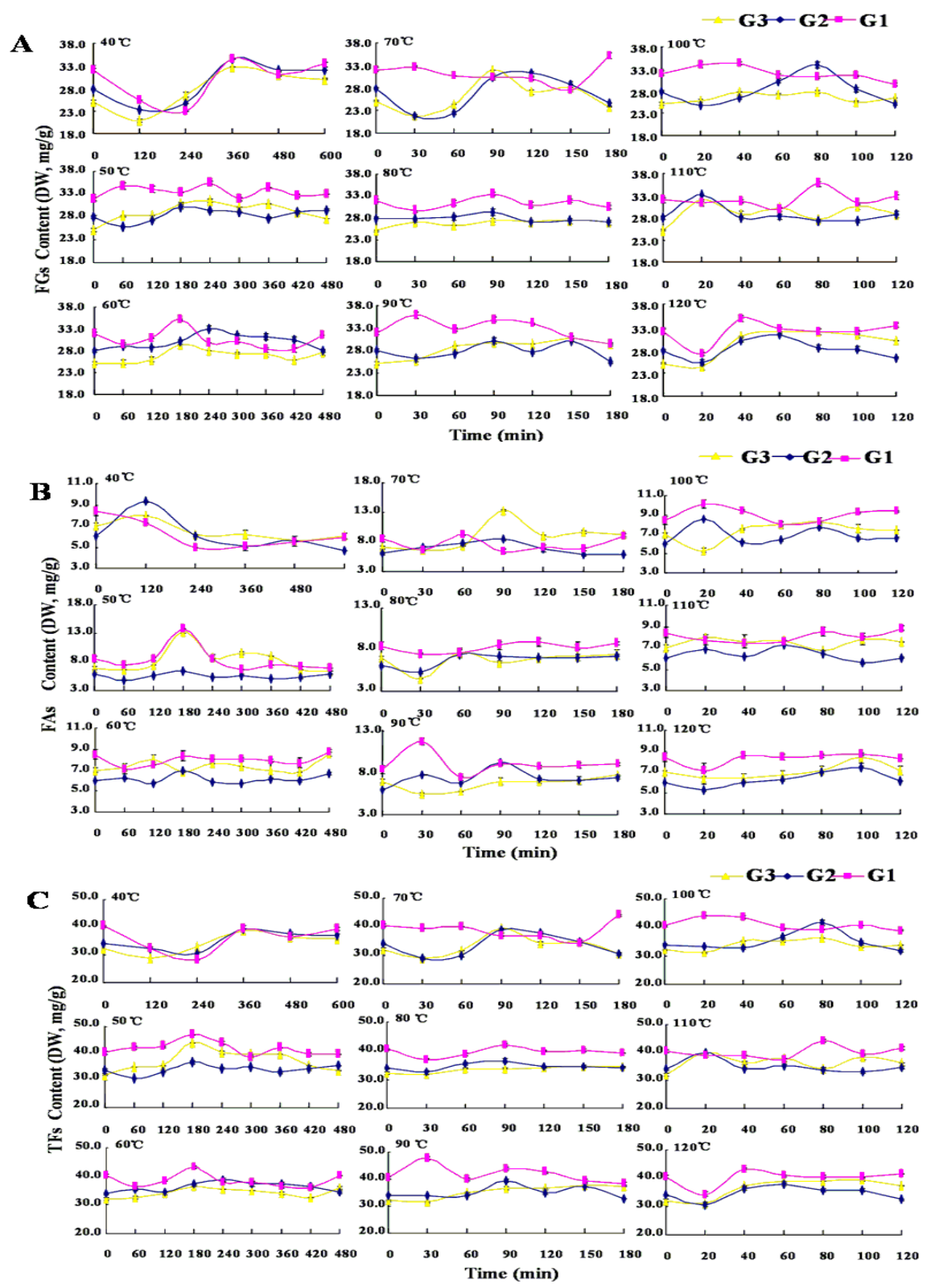


In the treatment sets of $\mathbf{G 1}$, the maximal $A$-values of the total contents of both flavonoid-glucosides (FGs) and TFs were at $90{ }^{\circ} \mathrm{C}$ for $30 \mathrm{~min}$, which were $35.91 \pm 0.61 \mathrm{mg} / \mathrm{g} \mathrm{DW}$ and $47.64 \pm 0.50 \mathrm{mg} / \mathrm{g}$ DW, respectively. While the maximal $A$-value of the total content of flavonoid aglycones (FAs), which were $13.74 \pm 0.05 \mathrm{mg} / \mathrm{g}$ DW appeared at $50{ }^{\circ} \mathrm{C}$ for $180 \mathrm{~min}$. Compared to those of fresh G1, the amounts of FGs, FAs and TFs were increased by $12.29 \%, 62.80 \%$ and $17.86 \%$, respectively. In the treatment sets of G2, the maximal A-values of FGs and FAs were observed at $40{ }^{\circ} \mathrm{C}$ for $360 \mathrm{~min}$ and $120 \mathrm{~min}$, respectively, $34.64 \pm 0.57 \mathrm{mg} / \mathrm{g}$ DW and $9.71 \pm 0.04 \mathrm{mg} / \mathrm{g} \mathrm{DW}$, respectively, The maximal $A$-values of TFs were at $100{ }^{\circ} \mathrm{C}$ for $80 \mathrm{~min}$, which were $41.68 \pm 0.82 \mathrm{mg} / \mathrm{g} \mathrm{DW}$. The amounts of FGs, FAs and TFs increased $23.71 \%, 61.56 \%$ and $22.59 \%$, respectively, compared to those in fresh G2. In the treatment sets of G3, the maximal contents of FAs $(13.35 \pm 0.40 \mathrm{mg} / \mathrm{g} \mathrm{DW})$ and TFs $(44.10 \pm$ $0.08 \mathrm{mg} / \mathrm{g} \mathrm{DW}$ ) were achieved at $50{ }^{\circ} \mathrm{C}$ for $180 \mathrm{~min}$, increased $90.99 \%$ and $37.34 \%$ respectively, compared to those in fresh G3, while the maximal $A$-values of FGs $(32.74 \pm 0.40 \mathrm{mg} / \mathrm{g} \mathrm{DW})$ was at $40{ }^{\circ} \mathrm{C}$ for 360 min with an increase of $30.33 \%$ to those of the fresh G3 (Figure 3).

It is generally acknowledged that the contents of bioactive components in medicinal plants are accumulated in the pre-harvest and decrease in the post-harvest drying process along with the increase of temperature and the prolonging of treatment [27]. The results obtained from the present study showed that both low and high temperature drying treatments could lead to significant dynamic changes of the flavonoids contents in the rhizomes of $B$. chinensis during the thermal drying process. The change rates of flavonoids in the same grade of the rhizome during thermal drying process at the different temperatures were varied. At lower temperatures, the increase amounts of flavonoids at first in the early stages of thermal drying processes might be explained by the fact that the rhizome in drying process may be induced a series of stress resistance reactions. It is speculated that the fresh rhizome of $B$. chinensis remained physiologically active after harvested. The high temperature and dewatering stress on the plant might induce its physiological reaction and a lot of amount of reactive oxygen species (ROS) might be produced. Excess ROS might cause oxidative stress which could result in injury to plant at both the molecular and cellular level [28]. To avoid oxidative injury to the plant itself, excess ROS amounts might be particularly scavenged by antioxidant metabolites of plant [29]. During the thermal drying process of $B$. chinensis rhizome at low temperature, many biochemical reactions with the action of enzymes occur in the plant, which result in an increased amount of flavonoids that might be used as antioxidants [30-32], but this hypothesis needs further research to be confirmed. As the temperature increases, the enzymes in the plant will be deactivated and the cell walls will break down, and thereby the bonding forces between flavonoids and tissue matrix are weakened, leading to more flavonoids being released and higher contents of total flavonoids are detected [33]. Similar phenomena have been reported with some types of secondary metabolites in other medicinal or food materials such as Salvia miltiorrhiza ("Danshen" in chinese), North American Ginseng, maca (Lepidium meyenii) and tomato [22,33-35].

The change of the individual flavonoid content within the same grade of the rhizome was different during the thermal drying process at the different treatment temperatures. The fresh rhizome contained the highest amount of tectorigenin (7), which decreased during the drying process at all tested temperatures. It is possible that tectorigenin is more thermo-labile than other flavonoids, even at the low temperature. It is possible that tectorigenin was consumed first as an antioxidant during the drying process. 
Irisflorentin (10), a flavonoid aglycone, is the chemical marker used for the quality control of Belamcandae Rhizoma, and minimum content of this component in the commercial materials of this herb should be no less than $0.10 \%$ as documented in the Chinese Pharmacopoeia [1]. The variation of the contents of mangiferin (2), iristectorigenin A (8), irigenin (9), irilone (11) and dichotomitin (12), were positively correlated with irisflorentin (10) $(p<0.01)$ (Figure 4). Interestingly, all of those flavonoids distribute mainly in the external cork cells layer of the rhizomes.

Although the amounts of the flavonoids in the rhizome of B. chinensis were increased in the early stages during thermal drying process, the efficiencies of thermal drying process under different treatment temperatures were varied. Table 1 showed the contents of the 12 flavonoids in the three grades of the rhizome at the sampling point when the moisture met the standard $(\leq 10.0 \%)$.

Figure 4. The correlations between irisflorentin and the compound 2, 8, 9, 11 and 12. 2, mangiferin; 8, iristectorigenin A; 9, irigenin; 11, irilone; 12, dichotomitin. ( $\mathrm{PC}$ is the Pearson Correlation between irisflorentin and the compound 2, 8, 9, 11and 12, respectively).
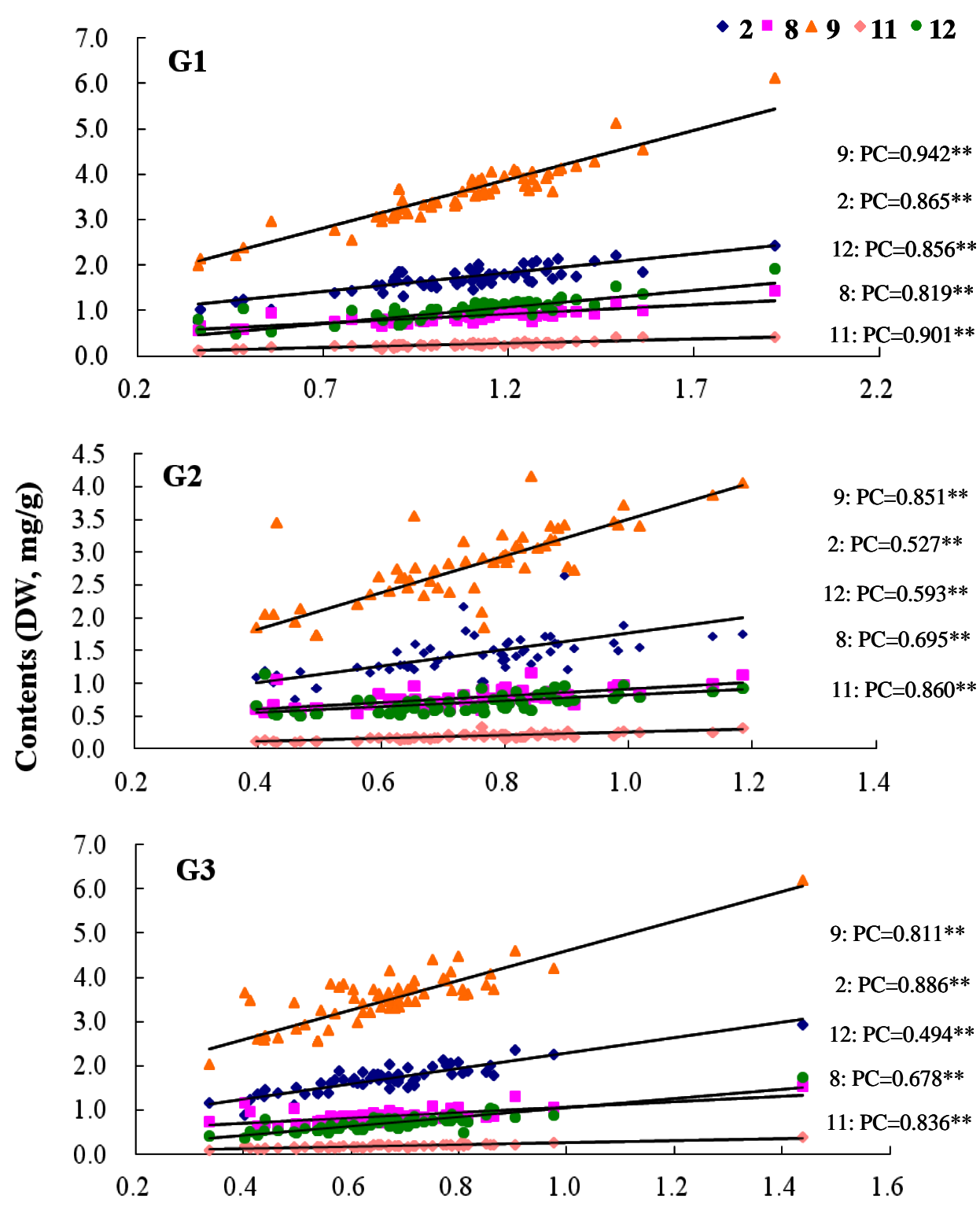

Irisflorentin Contents (DW, mg/g) 
In order to clarify the efficiency of thermal drying process for three grades of $B$. chinensis, the increase rate of flavonoid content was calculated with the following equation:

$$
\mathbf{I F}=(\mathbf{S}-\mathbf{F}) / \mathbf{F} \times 100 \%
$$

Where IF is the increase rate of flavonoid content $(\%), \mathbf{S}$ is the flavonoid content in the three grades of the rhizome at the sampling point when the moisture met the standard $(\leq 10.0 \%)(\mathrm{DW}, \mathrm{mg} / \mathrm{g})$ and $\mathbf{F}$ is the flavonoid content in the fresh rhizome $(\mathrm{DW}, \mathrm{mg} / \mathrm{g}$ ). When IF value is positive indicate increasing the amount of flavonoid, and negative value indicates decreasing the amount of flavonoid. The IF values obtained for the three grades samples of the rhizome at different treatment temperatures were shown in Table 2. The IF values of FGs, FAs and TFs from each grade treated at $100{ }^{\circ} \mathrm{C}$ showed positive values, which were $6.88 \%, 12.53 \%$ and $8.06 \%$ for G1, $8.42 \%, 6.66 \%$ and $8.11 \%$ for G2, and $8.30 \%, 13.90 \%$ and $9.52 \%$ for G3, respectively. While all IF values of FGs, FAs and TFs from each grade treated at $120{ }^{\circ} \mathrm{C}$ were negative indicated that the flavonoids contents were all decreased at this treatment temperature. Most of IF values of FGs were positive ones except those of $\mathbf{G 1}$ sets at $70{ }^{\circ} \mathrm{C}$, $110{ }^{\circ} \mathrm{C}$ and $120^{\circ} \mathrm{C}$ treatment, $\mathbf{G 2}$ sets at $90{ }^{\circ} \mathrm{C}$ and $120{ }^{\circ} \mathrm{C}$ treatment. In contrast, most of IF values of FAs for $\mathbf{G 1}$ sets were negative except those of $80{ }^{\circ} \mathrm{C}$ and $100{ }^{\circ} \mathrm{C}$ treatment. As to IF values of FAs for G2 sets, those of low temperature $\left(40^{\circ} \mathrm{C}, 50^{\circ} \mathrm{C}, 60^{\circ} \mathrm{C}\right.$ and $\left.70{ }^{\circ} \mathrm{C}\right)$ treatment were negative while those of high temperature $\left(80^{\circ} \mathrm{C}, 90^{\circ} \mathrm{C}, 100^{\circ} \mathrm{C}\right.$ and $\left.110^{\circ} \mathrm{C}\right)$ treatment were positive. IF values of FAs for G3 sets, those of treatment at $40{ }^{\circ} \mathrm{C}, 50{ }^{\circ} \mathrm{C}, 80{ }^{\circ} \mathrm{C}$ and $120{ }^{\circ} \mathrm{C}$ were negative, while those of treatment at $60{ }^{\circ} \mathrm{C}, 90^{\circ} \mathrm{C}, 100{ }^{\circ} \mathrm{C}$ and $110^{\circ} \mathrm{C}$ were positive. Most of IF values of TFs for G1 were negative ones except those of $60{ }^{\circ} \mathrm{C}, 80^{\circ} \mathrm{C}$ and $100^{\circ} \mathrm{C}$ treatment. All of IF values of TFs for G2 and G3 sets except that of $120{ }^{\circ} \mathrm{C}$ treatment were positive. This result implicated that the optimal drying temperature for the rhizomes of $\mathrm{B}$. chinensis should be $60{ }^{\circ} \mathrm{C}, 80^{\circ} \mathrm{C}$ and $100{ }^{\circ} \mathrm{C}$. When the production effectiveness is taken into consideration, the most appropriate temperature for $B$. chinensis drying process is suggested to be $100{ }^{\circ} \mathrm{C}$.

Table 2. The rate of increase of flavonoid contents when the moisture reached the standard.

\begin{tabular}{|c|c|c|c|c|c|c|c|c|c|c|}
\hline & $\mathrm{CF}^{\mathrm{a}}$ & $40{ }^{\circ} \mathrm{C}$ & $50{ }^{\circ} \mathbf{C}$ & $60^{\circ} \mathrm{C}$ & $\mathbf{7 0}^{\circ} \mathrm{C}$ & $80^{\circ} \mathrm{C}$ & $90^{\circ} \mathrm{C}$ & $100^{\circ} \mathrm{C}$ & $110{ }^{\circ} \mathrm{C}$ & $120{ }^{\circ} \mathrm{C}$ \\
\hline \multirow{3}{*}{ G1 } & FGs (\%) & 4.28 & 2.16 & 9.47 & -5.75 & 4.68 & 1.98 & 6.88 & -0.85 & -14.85 \\
\hline & FAs $(\%)$ & -29.39 & -14.24 & -1.59 & -17.68 & 1.46 & -12.14 & 12.53 & -12.84 & -14.79 \\
\hline & TFs (\%) & -2.75 & -1.26 & 7.16 & -8.24 & 4.01 & -0.97 & 8.06 & -3.36 & -14.84 \\
\hline \multirow{3}{*}{ G2 } & FGs (\%) & 14.75 & 3.81 & 18.28 & 2.93 & 4.69 & -2.07 & 8.42 & 0.47 & -9.63 \\
\hline & FAs $(\%)$ & -21.90 & -12.39 & -2.60 & -3.41 & 19.83 & 12.26 & 00 & 2.93 & -13.17 \\
\hline & TFs (\%) & 8.28 & 0.94 & 14.59 & 1.81 & 7.36 & 0.46 & 8.11 & 0.91 & -10.25 \\
\hline \multirow{3}{*}{ G3 } & FGs $(\%)$ & 19.79 & 15.08 & 11.67 & 8.21 & 8.59 & 19.21 & 8.30 & 13.78 & -3.11 \\
\hline & FAs $(\%)$ & -13.56 & -5.48 & 8.88 & 27.34 & -6.80 & 0.02 & 13.90 & 8.90 & -7.65 \\
\hline & TFs $(\%)$ & 12.54 & 10.61 & 11.06 & 6.70 & 5.24 & 15.03 & 9.52 & 12.71 & -4.10 \\
\hline
\end{tabular}

${ }^{\mathrm{a}} \mathbf{I F}$ is the increase rate of flavonoid content $(\%)$. 


\section{Experimental Section}

\subsection{Plant Materials}

Fresh two-year-old rhizomes of B. chinensis were collected from Tuanfeng County, Hubei Province in China, during the harvest season in October 2012 and were authenticated by one of the authors, Dr Minjian Qin. The voucher specimens (CMR00001MT017) were deposited in the Department of Resources Science of Traditional Chinese Medicines, China Pharmaceutical University, Nanjing, China. The fresh rhizomes were transported to the laboratory within two days and the soil was removed with a dry towel. Then the rhizome samples were immediately separated into three parts, namely the primary grade (grade I rhizome, G1), the second grade (grade II rhizome, G2) and the third grade (grade III rhizome, G3) as shown in Figure 1A, according to the levels of growth and development as described above. The raw materials were sliced into $2 \sim 3 \mathrm{~mm}$ pieces. The sliced materials were selected for uniform size, mixed well and stored at $-20^{\circ} \mathrm{C}$ until assay.

\subsection{Drying Process}

The sliced fresh materials were dried at different temperatures ranging from $40{ }^{\circ} \mathrm{C}$ to $120{ }^{\circ} \mathrm{C}$ in $10{ }^{\circ} \mathrm{C}$ intervals using a thermostatic oven. The sampling interval and frequency at each temperature were determined according to the difference of drying efficiency, specifically, $2 \mathrm{~h}$ intervals in total $10 \mathrm{~h}$ for $40{ }^{\circ} \mathrm{C} ; 1 \mathrm{~h}$ intervals in total $8 \mathrm{~h}$ for $50{ }^{\circ} \mathrm{C}$ and $60{ }^{\circ} \mathrm{C} ; 30 \mathrm{~min}$ intervals in total $3 \mathrm{~h}$, for $70{ }^{\circ} \mathrm{C}, 80^{\circ} \mathrm{C}$ and $90{ }^{\circ} \mathrm{C} ; 20 \mathrm{~min}$ intervals in total $2 \mathrm{~h}$ for $100{ }^{\circ} \mathrm{C}, 110{ }^{\circ} \mathrm{C}$ and $120^{\circ} \mathrm{C}$. The sliced raw materials $(\sim 10.0 \mathrm{~g})$ were weighted and medially placed on a watch glass $(9.0 \mathrm{~cm}$ in diameter). Prior to put into the materials, the oven was preheated to the set temperature. At each sampling point, two batches (one for moisture determination, the other for contents determination) with each on three watch glasses, were randomly taken from the oven during the drying process. The processed materials were cooled to the room temperature in a desiccator, then grounded and sieved with 80 mesh sieve and weighed accurately.

\subsection{Determination of Moisture}

The results of the pre-experiment suggested that there was no significant difference between the drying method recommended in the Chinese Pharmacopoeia [1] and the method using a digital moisture analyzer. Detailed data are shown in Supplementary Material Table S5. The latter method could solve some problems such as a long time drying and tedious operation. The moisture of samples from different sampling points was determined in triplicate by a digital moisture analyzer (Satorius, MA35, Gottingen, Germany) at $105^{\circ} \mathrm{C}$.

\subsection{Chemicals and Reagents}

Reference compounds including neomangiferin (1), mangiferin (2), tectoridin (3), iristectorin B (4), iristectorin A (5), iridin (6), tectorigenin (7), iristectorigenin A (8), irigenin (9), irisflorentin (10), irilone (11) and dichotomitin (12) were isolated and purified from the dried rhizomes of $B$. chinensis (L.) DC. or Iris tectorum Maxim. in our laboratory [5,6,36]. Their structures were identified by UV, IR, MS, ${ }^{1} \mathrm{H}-\mathrm{NMR}$ and ${ }^{13} \mathrm{C}-\mathrm{NMR}$, and the purity of each compound was determined to be over $98 \%$ by 
an HPLC-UV method. HPLC grade acetonitrile (Merck, Darmstadt, Germany) was used for HPLC analysis. Ultra-pure water was purified from a ULUP-II-20T purification system (ULUP, Nanjing, China); analytical grade acetic acid (Nanjing Reagent, Jiangsu, China) and HPLC grade methanol (Hanbang, Jiangsu, China) were used for sample preparation.

\subsection{Sample Preparation}

The dry powders $(\sim 0.10 \mathrm{~g})$ of Belamcandae Rhizoma were extracted twice with $75 \%$ methanol $(20 \mathrm{~mL})$ in an ultrasonic bath at room temperature for $30 \mathrm{~min}$. The extracted solution was centrifuged at 3,000 rpm for $10 \mathrm{~min}$, then combined and diluted with $75 \%$ methanol to $25 \mathrm{~mL}$. The solution was filtered through a $0.45 \mu \mathrm{m}$ membrane filter before HPLC analysis. Triplicate samples for each sampling point were analyzed.

\subsection{Chromatographic Conditions}

An Agilent 1100 Series HPLC instrument equipped with a UV detector, a quaternary pump, a column heater-cooler (Agilent Corporation, Palo Alto, CA, USA), a vacuum degasser and a $20 \mu \mathrm{L}$ sample loop manual injector was used for sample analysis. The column configuration was an Agilent Zorbax SB-C $\mathrm{C}_{18}$ column $(250 \mathrm{~mm} \times 4.6 \mathrm{~mm}, 5 \mu \mathrm{m})$ with an Alltech Associates $\mathrm{C}_{18}$ guard column $(7.5 \mathrm{~mm} \times 4.6 \mathrm{~mm}, 5 \mu \mathrm{m})$. The column temperature was maintained at $30{ }^{\circ} \mathrm{C}$. The mobile phase consisted of solvent A (water-acetic acid (100:0.4, v/v)) and B (acetonitrile). The gradient elution program was used as follows: $8 \%-17 \%$ B in $0-15 \mathrm{~min}, 17 \%-20 \% \mathrm{~B}$ in $15-35 \mathrm{~min}, 20 \% \mathrm{~B}$ in $35-40 \mathrm{~min}$, $20 \%-26 \% \mathrm{~B}$ in $40-65 \mathrm{~min}$ and $40 \%-50 \% \mathrm{~B}$ in $65-75 \mathrm{~min}$. The flow rate was $1.0 \mathrm{~mL} / \mathrm{min}$. The injection volume was $20 \mu \mathrm{L}$. The detection wavelength was set at $269 \mathrm{~nm}$ for all the tested compounds.

\subsection{Calibration and Method Validation}

Known amounts of standards were dissolved and diluted with methanol to provide a series of standard solutions. The mixed standard stock solution containing 12 reference compounds were serially diluted for the construction of calibration curves at six concentrations. The limits of detection (LOD) and quantification (LOQ) were determined at a signal-to-noise ( $\mathrm{S} / \mathrm{N})$ ration of 3 and 10, respectively.

The intra-day variability was performed six times within one day, and the inter-day variability was obtained from nine determinations in three consecutive days (three determinations per day). The recovery tests were performed by spiking a known amount of 12 standards into a Belamcandae Rhizoma sample and extracting as described above. All standard solutions of various concentrations were stored at $4{ }^{\circ} \mathrm{C}$ until assay. Each test was analyzed in triplicate.

\subsection{Statistical Analysis}

All data were the mean values from three samples in each sampling point and statistically analyzed by SPSS version 16.0 for Windows (SPSS Inc., Chicago, IL, USA). The least significant differences (LSD; $p=0.05$ ), one way analysis of variance (ANOVA) and the bivariate correlation were calculated from each analysis. 


\section{Conclusions}

This study revealed the differences of the contents of main flavonoids among the three subunit levels of the fresh rhizomes. The results indicated that the elder parts of the fresh rhizome contained higher amounts of flavonoids than the junior ones. The dynamic variation patterns of the amounts of flavonoids in the rhizome during the thermal drying process were obtained. Most of individual flavonoid contents in the rhizome increased in the early stages of the drying processes and decreased as the processes were prolonged. It is speculated that rhizomes of B. chinensis remained physiologically active after harvest and the stress resistance mechanisms of plants might be involved in the early stage of the herb drying process. The reasons for the flavonoid content variation in the rhizome of $B$. chinensis during thermal drying processing needs to be further studied. Taking into account production effectiveness and flavonoid yields, the appropriate drying temperature for this herb was suggested to be $100{ }^{\circ} \mathrm{C}$. These findings should facilitate the production of herbal products of rhizomes of $B$. chinensis with consistency and maximum flavonoid content.

\section{Supplementary Materials}

Supplementary Materials can be accessed at: http://www.mdpi.com/1420-3049/19/7/10440/s1.

\section{Acknowledgments}

This work was supported by the National Natural Science Foundation of China (Grant No. 81373918), National Major Scientific and Technological Special Project for "Significant New Drugs Development" during the Twelfth Five-year Plan Period (Grant No. 2012ZX09304006) and the Fundamental Research Funds for the Central Universities (JKQ2011038 and PT2014ZY0086).

\section{Author Contributions}

YZ and MJQ designed research; YZ, BQP, FYX and GYX performed research and all authors analyzed the data; YZ, BQP and MJQ wrote the paper. All authors read and approved the final manuscript.

\section{Conflicts of Interest}

The authors declare no conflict of interest.

\section{References}

1. Chinese Pharmacopoeia Committee. Pharmacopoeia of the People's Republic of China; Chinese Medical Science and Technology Press: Beijing, China, 2010; Volume 1, pp. 267-268.

2. Ha, S.C.; Won, S.W. Flavonoids from the rhizomes of Belamcanda chinesis. Arch. Pharm. Res. 1991, 14, 357-358.

3. Woo, W.S.; Woo, E.H. An Isoflavone noririsfiorentin from Belamcanda chinensis. Phytochemistry 1993, 33, 939-940.

4. Ito, H.; Onoue, S.; Yoshida, T. Isoflavonoids from Belamcanda chinensis. Chem. Pharm. Bull. 2001, 49, 1229-1231. 
5. Ji, W.L.; Qin, M.J.; Wang, Z.T. Studies on the constituents of Belamcanda chinensis (I). J. China Pharm. Univ. 2001, 32, 197-199.

6. Qin, M.J.; Ji, W.L.; Wang, Z.T. Study on chemical constituents of Belamcanda chinensis (I). Chin. Tradit. Herb. Drugs 2004, 35, 487-489.

7. Seidlova, W.D.; Hesse, O.; Jarry H.; Rimoldi, G.; Thelen, P.; Christoffel, V.; Wuttke, W. Belamcanda chinensis and the thereof purified tectorigenin have selective estrogen receptor modulator activities. Phytomedicine 2004, 11, 392-403.

8. Li, J.; Li, W.Z.; Huang, W.; Cheung, A.W.; Bi, C.W.; Duan, R.; Guo, A.J.; Dong, T.T.; Tsim, K.W. Quality evaluation of Rhizoma Belamcanda (Belamcanda chinensis (L.) DC.) by using high-performance liquid chromatography coupled with diode array detector and mass spectrometry. J. Chromatogr. A 2009, 1216, 2071-2078.

9. Qin, M.J.; Tanaka, T.; Yu, G.D.; Ji, W.L.; Wang, Z.T. Biological Research of Belamcanda chinensis. J. Chin. Med. Mater. 2003, 1, 4-5.

10. Li, P.; Qi, L.W.; Wen, X.D.; Sheng, L.H. Methods for the elucidation of bioactive components and quality control of Traditional Chinese Medicines. Chin. J. Nat. Med. 2007, 5, 1-9.

11. Pan, L.H.; Li, X.F.; Wang, M.N.; Zha, X.Q.; Yang, X.F.; Liu, Z.J.; Luo, Y.B.; Luo, J.P. Comparison of hypoglycemic and antioxidative effects of polysaccharides from four different Dendrobium species. Int. J. Biol. Macromol. 2014, 64, 420-427.

12. Wan, J.B.; Yang, F.Q.; Li, S.P.; Wang, Y.T.; Cui, X.M. Chemical characteristics for different parts of Panax notoginseng using pressurized liquid extraction and HPLC-ELSD. J. Pharm. Biomed. 2006, 41, 1596-1601.

13. Peng, R.; Ma, P.; Mo, R.; Sun, N. Analysis of the bioactive components from different growth stages of Fritillaria taipaiensis P.Y. Li. Acta Pharm. Sin. B 2013, 3, 167-173.

14. Claudia, D.B.; Silvia, T.; Marco, M.; Luciana, G.A. Changes in soil chemical parameters and organic matter balance after 13 years of ramie [Boehmeria nivea (L.) Gaud.] cultivation in the Mediterranean region. Eur. J. Agron. 2011, 35, 154-163.

15. Mhamdi, B.; Aidi Wannes, W.; Sriti, J.; Jellali, I.;Ksouri, R.; Marzouk, B. Effect of harvesting time on phenolic compounds and antiradical scavenging activity of Borago officinalis seed extracts. Ind. Crop. Prod. 2010, 31, e1-e4.

16. Shan, G.S.; Zhang, L.X.; Zhao, Q.M.; Xiao, H.B.; Zhuo, R.J.; Xu, G., Jiang H.; You X.M.; Jia, T.Z. Metabolomic study of raw and processed Atractylodes Macrocephala Koidz by LC-MS. J. Pharm. Biomed. Anal. 2014, 16, 74-84.

17. Rinaldi, R.; Amodio, M.L.; Colelli, G. Effect of temperature and exogenous ethylene on the physiological and quality traits of purslane (Portulaca oleracea L.) leaves during storage. Postharvest Biol. Technol. 2010, 58, 147-156.

18. Davidson, V.; Li, X.; Brown, R. Forced-air drying of ginseng root: 1. Effects of air temperature on quality. J. Food Eng. 2004, 63, 361-367.

19. Tankoa, H.; Carriera, D.J.; Duana, L.; Clausena, E. Pre-and post harvest processing of medicinal plants. Plant Genet. Res. 2005, 3, 304-313.

20. Martynenko, A.I.; Brown, R.B.; Davidson, V.J. Physical and physiological factors of ginseng drying. Appl. Eng. Agric. 2006, 22, 571-576. 
21. Harbourne, N.; Marete, E.; Jacquier, J.C.; Oriordan, D. Effect of drying methods on the phenolic constituents of meadowsweet (Filipendula ulmaria) and willow (Salix alba). LWT Food Sci. Technol. 2009, 42, 1468-1473.

22. Li, X.B.; Wang, W.; Zhou, G.J.; Li, Y.; Xie, X.M.; Zhou, T.S. Production of salvianolic acid in roots of Salvia miltiorrhiza (Danshen) during the harvest drying process. Molecules 2012, 17, 2388-2407.

23. Morrissey, C.; Bektic, J.; Spengler, B.; Galvin, D.; Christoffel, V.; Klocker, H.; Fitzpatrick, J.M. Phytoestrogens derived from Belamcanda chinensis have an antiproliferative effect on prostate cancer cells in vitro. J. Urol. 2004, 172, 2426-2433.

24. Wozniak, D.; Janda, B.; Kapusta, I. Antimutagenic and anti-oxidant activities of isoflavonoids from of Belamcanda chinensis (L.) DC. Mutat. Res.-Genet. Toxicol. Environ. Mutagen. 2010, 696, 148-153.

25. Hasibeder, A.; Venkataramani, V.; Thelen, P. Phytoestrogens regulate the proliferation and expression of stem cell factors in cell lines of malignant testicular germ cell tumors. Int. J. Oncol. 2013, 43, 1385-1394.

26. Wang, Y.J.; Peng, H.S.; Shen, Y.; Zhao, R.; Huang, L.Q. The profiling of bioactive ingredients of differently aged Salvia miltiorrhiza roots. Microsc. Res. Tech. 2013, 76, 947-954.

27. Bruni, R.; Sacchetti, G. Factors affecting polyphenol biosynthesis in wild and field grown St. John's Wort (Hypericum perforatum L. Hypericaceae/Guttiferae). Molecules 2009, 14, 682-725.

28. Dat, J.; Vandenabeele, S.; Vranová, E.; van Montagu, M.; Inzé, D.; van Breusegem, F. Dual action of the active oxygen species during plant stress responses. Cell Mol. Life Sci. 2000, 57, 779-795.

29. Golldack, D.; Li, C.; Mohan, H.; Probst, N. Tolerance to drought and salt stress in plants: Unraveling the signaling networks. Front. Plant Sci. 2014, 5, 151.

30. Hartmann, T. From waste products to ecochemicals: Fifty years research of plant secondary metabolism. Phytochemistry 2007, 68, 2831-2846.

31. Qin, M.J.; Ji, W.L.; Liu, J.; Zhao, J.; Yu, G.D. Scavenging effects on radicals of isoflavones from rhizome of Belamcanda chinensis. Chin. Tradit. Herb. Drugs 2003, 34, 640-642.

32. Shu, P. Quality Evaluation of Several Medicinal Plants from Iridaceae and the Pharmacological Efficacy Studies on Main Bioactive Constituents. Ph.D. Thesis, China Pharmaceutical University, Nanjing, China, 2010; pp. 132-148.

33. Chang, C.H.; Lin, H.Y.; Chang, C.Y.; Chuan, L.Y. Comparisons on the antioxidant properties of fresh, freeze-dried and hot-air-dried tomatoes. J. Food Eng. 2006, 77, 478-485.

34. Ren, G.; Chen, F. Drying of North American Ginseng (Panax quinquefolium) roots by microwave-hot air combination. J. Food Eng. 1998, 35, 433-443.

35. Yabar, E.; Pedreschi, R.; Chirinose, R.; Campos, D. Glucosinolate content and myrosinase activity evolution in three maca (Lepidium meyenii Walp.) ecotypes during preharvest, harvest and postharvest drying. Food Chem. 2011, 127, 1576-1583.

36. Shang, H.Q.; Qin, M.J.; Wu, J.R. Constituents of rhizomes of Iris tectorum. Chin. J. Nat. Med. 2007, 5, 312-314.

Sample Availability: Samples of tectoridin, iridin, tectorigenin, irigenin are available from the authors.

(C) 2014 by the authors; licensee MDPI, Basel, Switzerland. This article is an open access article distributed under the terms and conditions of the Creative Commons Attribution license (http://creativecommons.org/licenses/by/3.0/). 